\title{
漁具監視における漂流船位の推定
}

$$
\begin{aligned}
& \text { 平岩 節*.斎藤昭二**石井 清彦* } \\
& \text { 安間 元 }{ }^{*} \text { 米田国三郎 }
\end{aligned}
$$

\section{A Method of Estimating the Relative Position of a Ship to her Fishing Gear during Drifting}

\author{
T. Hiraiwa, S. Saito, K. Ishii, \\ G. Anma and K. Yoneta
}

\begin{abstract}
An officer on duty on a fishing vessel watches the fishing gear drifting after setting the salmon gill-net or tuna longline.

At any time, if he can estimate his ship's position by any method concerning the gear without recourse to an object (flag, light, reflector, radio buoy), he can employ the method to watch the gear effectively. The authors had experimented with the drifting of the Hokuseimaru (273 G/T), and reported that the direction and distance of drifting were estimated by the ship's head and wind velocity. And for the next study, we experimented on the accuracies of estimated ship's positions based on the method, in the North Pacific Ocean.

The experiment

1. As the drifting velocity and directions had been calculated by previously reported equations, some drifting positions were estimated.

2. Ship's positions can be determined by the bearings and distances of the corner reflector connected to the gill-net (length 3 n. m., depth $7 \mathrm{~m}$ ).

3. Determined and estimated ship's positions are shown in Fig. 2 every 30 minutes. The accuracies of estimated positions.

1. We say that the distance error is the length between the determined position and the estimated position, as shown in Fig. 3, related to the drifting time every day. Furthermore standard deviations of distance errors are shown in Fig. 4.

2. Differences of estimated drifting directions from determined directions are shown in Fig. 5 in relation with the drifting time. And standard deviations of direction errors are shown in Fig. 6.

3. Under the general condition that the drifting time is 6 to 8 hours, the distance error is 1 n.m. (s.d.) and the direction error is $7^{\circ}$ (s. d.).

According to this method, we could obtain satisfactory results from various points of view for

* 北海道大学水産学部 (函館市港町)
\end{abstract}


the sake of keeping watch over the fishing gear.

We recommend an officer on duty to study the drifting characteristics of his own ship and apply himself to keeping watch over a fishing gear.

\section{1. 緒言}

船に drift を生ぜしめる要因は，上部構造物に働く風圧力，風によつて起こされた吹送流，波 浪による横動摇のために誘起せられる横漂流，更には海流・潮流の影響である。この圧流作用を 把握することは，航走中においては針路の更正，船位の推定に不可欠であり，また出入港時にお けるがごとく低速状態にあつては操船にも関連がある。他方機関停止時の漂流慒難船の捜索 に，また漁船においては漁具（延縄，流網）監視の上から重要な問題で流る。

推進力を失つた遭難船, 推進を止めた操業漁船, いずれの場合も漂流位置推定はそれなりの意 義があるが，船位の表示法そのものは基本的に異なる。すなわち遭難船の場合は上記諸要因をこ とごとく推定加味し，現在位置を経緯度座標で表示する必要があるのに対し，操業漁船の場合 は，船も漁具も海流・潮流・吹送流の影響をほぼ等しく受けて流され，風については船のみ圧流 されるので，漁具を極，風向を原線とした極座標で表わさなければ意味がない。

現在とられている漁具監視の方法は目標（灯火，大旗，reflector）を視界内に保つよう漂流中 でも時々機関を運転して風上に遡うている。この定型行動の中にあつても，機関の修理手入れの ため長時閒連続漂流のこともあり，また目標の視認困難なこともあるが，いかなる不測の事態に 際しても，な掞万全の策をとることが要求される。また radio buoy による監視の場合は揚網, 揚縄近くまで連続漂流しても，目標の方向確認は可能であるが，帰投時間についての情報は得ら れない。また故障時の対策も考えておかなければ万全を期し難い。

筆者らは前報[1]において，一見 random にみえる漂流方向にも統計的法則性のあることを指 摘したが，推定した動徐，極角を現実に適用して実用性の価值評俩を試みた。

\section{2. 漂流船位の推定方法}

浮泛物は風压と水の流動によつて漂流する。漁具を監視する操業漁船の湯合，流れの複雑な海 域でない限り；風圧による船の漂流特性を知悉しておけげ，漁具に対する自船の漂流位置の推定 は可能である。（もちろん厳密な意味においては吃水，trim が変わると風圧流も当然異なるが， その変動は水線上下の投影面積比の平方根に比例すると見られるから，船の状態の変化に対する 配慮は要求する精度と提供される資料の精粗によつて推定者の判断に俟つべきものである。漂流 方响についても同じ。)

筆者らは北大練習船北星丸 $(273 \mathrm{G} / \mathrm{T})$ について昭和 42 年 6 月南千 島沖において漂流実験を行ない次の結果を得ている。

漂流速 $\mathrm{U}(\mathrm{kt})$ は減摇水槽作動 時で $0.143 \mathrm{~W}$, 停止時で $0.135 \mathrm{~W}$ $(\mathrm{W}$ ：風速 $\mathrm{m} / \mathrm{s})$, 風に対する船首方向 $(\alpha)$, 漂流方向 $(\beta)$ を図 1 のごとく測れば， $\alpha$ と $\beta$ の閒に注，水槽作動時，

$\beta^{\circ}=204^{\circ}-1.94 \alpha^{\circ}$, 停止時 $\beta^{\circ}=213^{\circ}-2.05 \alpha^{\circ}$

なる関係があつた。

この方法により任意時における漂流位置を推定せんとするのである が，吃水変化に対する漂流量の補正は，出入港時に抢ける平均吃水の 差が $10 \mathrm{~cm}$ 未満であることと，推定漂流方向・距離のばらつきとの関

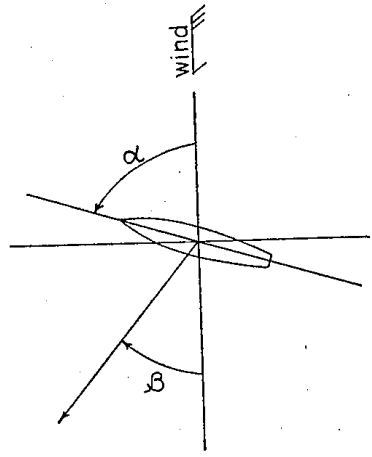

図 1 船首方向 $(\alpha)$, 漂 流方向 $(\beta)$ の測り方 
表 1

\begin{tabular}{|c|c|c|c|c|c|c|c|c|c|c|c|c|c|}
\hline $\begin{array}{l}\text { 観番 } \\
\text { 測 } \\
\text { 日号 }\end{array}$ & $\begin{array}{l}\text { 観 番 } \\
\text { 測 } \\
\text { 点 号 }\end{array}$ & $\begin{array}{l}\text { 漂 } \\
\text { 流 } \\
\text { 量 }\end{array}$ & 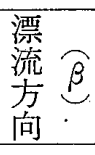 & 速 & $\begin{array}{c}\text { 船 } \\
\text { 真 } \\
\substack{\text { 古 } \\
\text { 占 }} \\
\end{array}$ & $\begin{array}{l}\text { タ. } \\
\text { ン } \\
\text { ク }\end{array}$ & $\begin{array}{l}\text { 観番 } \\
\text { 測 } \\
\text { 日号. } \\
\end{array}$ & $\begin{array}{l}\text { 観 番 } \\
\text { 測 } \\
\text { 点号 }\end{array}$ & $\begin{array}{l}\text { 漂 } \\
\text { 流 } \\
\text { 量 } \\
\end{array}$ & 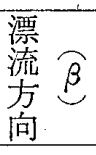 & 速 & 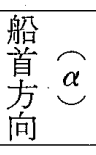 & $\begin{array}{l}\text { タ } \\
\text { ン } \\
\text { ク }\end{array}$ \\
\hline \multirow[t]{2}{*}{1} & \multirow[t]{2}{*}{$\begin{array}{r}1 \\
2 \\
3 \\
4 \\
5 \\
6 \\
7 \\
8 \\
9 \\
10\end{array}$} & \multirow[t]{2}{*}{$\begin{array}{l}0.17 \\
0.12 \\
0.26 \\
0.34 \\
0.26 \\
0.34 \\
0.30 \\
0.28 \\
0.32 \\
0.30\end{array}$} & \multirow[t]{2}{*}{$\begin{array}{l}93^{\circ} \\
31 \\
42 \\
13 \\
27 \\
35 \\
41 \\
52 \\
52 \\
74\end{array}$} & \multirow[t]{2}{*}{$\begin{array}{l}2.8 \mathrm{~m} \\
2.8 \\
3.3 \\
3.8 \\
3.3 \\
3.5 \\
3.5 \\
3.5 \\
3.8 \\
3.6\end{array}$} & \multirow[t]{2}{*}{$\begin{array}{l}68^{\circ} \\
88 \\
81 \\
91 \\
76 \\
82 \\
71 \\
68 \\
71 \\
74\end{array}$} & \multirow[t]{2}{*}{$\begin{array}{l}\text { 開 } \\
\prime \prime \\
\prime \prime \\
\prime \prime \\
\prime \prime \\
\prime \prime \\
\prime \prime \\
\prime \prime \\
\prime \prime \\
\prime \prime\end{array}$} & -6 & $\begin{array}{l}59 \\
60 \\
61 \\
62 \\
63 \\
64 \\
65 \\
66 \\
67 \\
68\end{array}$ & $\begin{array}{l}0.46 \\
0.50 \\
0.44 \\
0.45 \\
0.50 \\
0.53 \\
0.35 \\
0.32 \\
0.35 \\
0.45\end{array}$ & $\begin{array}{l}26^{\circ} \\
37 \\
46 \\
30 \\
44 \\
40 \\
22 \\
23 \\
39 \\
40\end{array}$ & $\begin{array}{l}6.8 \mathrm{~m} \\
6.0 \\
5.5 \\
5.5 \\
5.3 \\
5.0 \\
5.0 \\
5.0 \\
5.0 \\
5.3\end{array}$ & $\begin{array}{l}92^{\circ} \\
91 \\
88 \\
89 \\
92 \\
88 \\
98 \\
93 \\
91 \\
95\end{array}$ & $\begin{array}{l}\text { 開 } \\
\prime \prime \\
\prime \prime \\
\prime \prime \\
\prime \prime \\
\prime \prime \\
\text { 閉 } \\
\prime \prime \\
\prime \prime \\
\prime \prime\end{array}$ \\
\hline & & & & & & & \multirow[b]{4}{*}{8} & 69 & 0.54 & 42 & 6.8 & 92 & 開 \\
\hline \multirow[t]{2}{*}{2} & \multirow[t]{2}{*}{$\begin{array}{l}11 \\
12 \\
13 \\
14 \\
15 \\
16 \\
17 \\
18 \\
19 \\
20\end{array}$} & \multirow[t]{2}{*}{$\begin{array}{l}0.22 \\
0.23 \\
0.33 \\
0.33 \\
0.33 \\
0.35 \\
0.34 \\
0.30 \\
0.22 \\
0.19\end{array}$} & \multirow[t]{2}{*}{$\begin{array}{l}67 \\
57 \\
59 \\
42 \\
54 \\
63 \\
76 \\
80 \\
63 \\
66\end{array}$} & \multirow[t]{2}{*}{$\begin{array}{l}2.1 \\
2.9 \\
3.3 \\
3.8 \\
3.9 \\
4.2 \\
3.9 \\
3.1 \\
3.3 \\
2.9\end{array}$} & \multirow[t]{2}{*}{$\begin{array}{l}55 \\
68 \\
74 \\
81 \\
80 \\
64 \\
70 \\
67 \\
68 \\
65\end{array}$} & \multirow[t]{2}{*}{$\begin{array}{l}\text { 閉 } \\
\prime \prime \\
\prime \prime \\
\prime \prime \\
\prime \prime \\
\prime \prime \\
\prime \prime \\
\prime \prime \\
\prime \prime \\
\prime \prime\end{array}$} & & $\begin{array}{l}70 \\
71 \\
72 \\
73 \\
74 \\
75 \\
76 \\
77 \\
78\end{array}$ & $\begin{array}{l}0.66 \\
0.65 \\
0.63 \\
0.52 \\
0.55 \\
0.67 \\
0.62 \\
0.56 \\
0.50\end{array}$ & $\begin{array}{l}33 \\
25 \\
50 \\
39 \\
44 \\
47 \\
47 \\
39 \\
46\end{array}$ & $\begin{array}{l}6.8 \\
7.0 \\
7.3 \\
6.8 \\
7.0 \\
7.0 \\
6.8 \\
7.0 \\
7.0\end{array}$ & $\begin{array}{l}93 \\
89 \\
90 \\
88 \\
87 \\
84 \\
84 \\
84 \\
85\end{array}$ & $\begin{array}{l}11 \\
11 \\
11 \\
\prime \prime \\
\prime \prime \\
\text { 閉 } \\
\prime \prime \\
\prime \prime \\
\prime \prime\end{array}$ \\
\hline & & & & & & & & $\begin{array}{l}79 \\
80\end{array}$ & $\begin{array}{l}0.41 \\
0.42\end{array}$ & $\begin{array}{l}47 \\
42\end{array}$ & $\begin{array}{l}5.0 \\
5.0\end{array}$ & $\begin{array}{l}80 \\
81\end{array}$ & $\begin{array}{l}\text { 開 } \\
\prime \prime\end{array}$ \\
\hline \multirow{2}{*}{3} & $\begin{array}{l}21 \\
22 \\
23 \\
24 \\
25 \\
26\end{array}$ & $\begin{array}{l}0.39 \\
0.41 \\
0.46 \\
0.44 \\
0.42 \\
0.39\end{array}$ & $\begin{array}{l}42 \\
39 \\
44 \\
50 \\
50 \\
25\end{array}$ & $\begin{array}{l}4.8 \\
4.5 \\
5.0 \\
5.0 \\
5.3 \\
5.3\end{array}$ & $\begin{array}{l}87 \\
85 \\
81 \\
76 \\
74 \\
84\end{array}$ & $\begin{array}{l}\text { 閉 } \\
\prime \prime \\
\prime \prime \\
\prime \prime \\
\prime \prime \\
\prime \prime\end{array}$ & & $\begin{array}{r}81 \\
82 \\
83 \\
84 \\
85 \\
86 \\
\end{array}$ & $\begin{array}{l}0.45 \\
0.34 \\
0.36 \\
0.33 \\
0.32 \\
0.30\end{array}$ & $\begin{array}{l}65 \\
59 \\
59 \\
53 \\
75 \\
90\end{array}$ & $\begin{array}{l}4.3 \\
3.5 \\
3.3 \\
3.5 \\
3.0 \\
3.3\end{array}$ & $\begin{array}{l}88 \\
86 \\
83 \\
85 \\
65 \\
51\end{array}$ & $\begin{array}{l}\prime \prime \\
\prime \prime \\
11 \\
11 \\
\text { 閉 } \\
\prime \prime\end{array}$ \\
\hline & $\begin{array}{l}27 \\
28 \\
29 \\
30 \\
31 \\
32\end{array}$ & $\begin{array}{l}0.42 \\
0.42 \\
0.49 \\
0.40 \\
0.42 \\
0.41\end{array}$ & $\begin{array}{l}39 \\
41 \\
30 \\
46 \\
46 \\
47\end{array}$ & $\begin{array}{l}5.3 \\
5.5 \\
5.8 \\
5.5 \\
5.3 \\
5.0\end{array}$ & $\begin{array}{l}87 \\
83 \\
86 \\
89 \\
81 \\
81\end{array}$ & $\begin{array}{l}\prime \prime \\
\prime \prime \\
\prime \prime \\
\prime \prime \\
\prime \prime \\
\prime \prime\end{array}$ & \multirow[b]{2}{*}{9} & $\begin{array}{l}87 \\
88 \\
89 \\
90 \\
91 \\
92 \\
92\end{array}$ & $\begin{array}{l}0.33 \\
0.35 \\
0.28 \\
0.28 \\
0.24 \\
0.19\end{array}$ & $\begin{array}{r}-11 \\
-16 \\
-12 \\
-3 \\
-16 \\
1\end{array}$ & $\begin{array}{l}3.5 \\
3.5 \\
3.0 \\
3.0 \\
2.8 \\
3.0\end{array}$ & $\begin{array}{r}101 \\
99 \\
100 \\
99 \\
109 \\
111\end{array}$ & $\begin{array}{l}\text { 開 } \\
\prime \prime \\
\prime \prime \\
\prime \prime \\
\prime \prime \\
\prime \prime\end{array}$ \\
\hline \multirow[t]{2}{*}{4} & $\begin{array}{l}33 \\
34 \\
35 \\
36 \\
37 \\
38 \\
39\end{array}$ & $\begin{array}{l}0.31 \\
0.32 \\
0.27 \\
0.25 \\
0.26 \\
0.30 \\
0.31\end{array}$ & $\begin{array}{l}46 \\
40 \\
30 \\
47 \\
26 \\
17 \\
21\end{array}$ & $\begin{array}{l}2.9 \\
3.0 \\
3.5 \\
3.8 \\
4.3 \\
4.8 \\
5.0\end{array}$ & $\begin{array}{l}91 \\
93 \\
77 \\
82 \\
87 \\
91 \\
93\end{array}$ & $\begin{array}{l}\text { 開 } \\
\prime \prime \\
\prime \prime \\
\prime \prime \\
\prime \prime \\
\prime \prime \\
\prime \prime\end{array}$ & & $\begin{array}{r}94 \\
95 \\
96 \\
97 \\
98 \\
99 \\
100\end{array}$ & $\begin{array}{l}0.17 \\
0.17 \\
0.15 \\
0.21 \\
0.24 \\
0.21 \\
0.24 \\
0.20\end{array}$ & $\begin{array}{r}13 \\
16 \\
13 \\
36 \\
0 \\
30 \\
23\end{array}$ & $\begin{array}{l}3.0 \\
2.8 \\
2.8 \\
3.5 \\
3.8 \\
3.3 \\
3.3 \\
3.3\end{array}$ & $\begin{array}{r}104 \\
102 \\
92 \\
102 \\
94 \\
89 \\
91 \\
90\end{array}$ & $\begin{array}{l}11 \\
\prime \prime \\
\prime \prime \\
\prime \prime \\
\prime \prime \\
\prime \prime \\
\prime \prime\end{array}$ \\
\hline & $\begin{array}{l}40 \\
41 \\
42 \\
43 \\
44 \\
45 \\
46\end{array}$ & $\begin{array}{l}0.34 \\
0.36 \\
0.35 \\
0.35 \\
0.47 \\
0.46 \\
0.45\end{array}$ & $\begin{array}{l}28 \\
23 \\
44 \\
46 \\
23 \\
21 \\
25\end{array}$ & $\begin{array}{l}4.3 \\
3.8 \\
4.5 \\
5.0 \\
5.8 \\
6.0 \\
5.5\end{array}$ & $\begin{array}{l}87 \\
80 \\
82 \\
80 \\
85 \\
82 \\
88\end{array}$ & $\begin{array}{l}\prime \prime \\
\prime \prime \\
\prime \prime \\
\prime \prime \\
\prime \prime \\
\prime \prime\end{array}$ & \multirow[t]{2}{*}{10} & $\begin{array}{l}101 \\
102 \\
103 \\
104 \\
105 \\
106 \\
107\end{array}$ & $\begin{array}{l}0.23 \\
0.20 \\
0.29 \\
0.40 \\
0.35 \\
0.31 \\
0.33\end{array}$ & $\begin{array}{l}58 \\
61 \\
43 \\
54 \\
50 \\
48 \\
55\end{array}$ & $\begin{array}{l}2.5 \\
2.3 \\
3.5 \\
3.5 \\
3.0 \\
3.3 \\
3.8\end{array}$ & $\begin{array}{l}70 \\
75 \\
81 \\
76 \\
80 \\
79 \\
74\end{array}$ & $\begin{array}{l}\text { 開 } \\
\prime \prime \\
\text { 閉 } \\
\prime \prime \\
\prime \prime \\
\prime \prime \\
\prime \prime\end{array}$ \\
\hline \multirow[b]{2}{*}{5} & 47 & 0.27 & 9 & 4.0 & 102 & 閉 & & 108 & 0.31 & 57 & 3.8 & 76 & "I \\
\hline & $\begin{array}{l}48 \\
49 \\
50 \\
51 \\
52 \\
53 \\
54 \\
55 \\
56 \\
57 \\
58\end{array}$ & $\begin{array}{l}0.31 \\
0.33 \\
0.34 \\
0.42 \\
0.49 \\
0.41 \\
0.37 \\
0.42 \\
0.52 \\
0.57 \\
0.60\end{array}$ & $\begin{array}{r}-15 \\
0 \\
-16 \\
-15 \\
-20 \\
-4 \\
-9 \\
9 \\
10 \\
6 \\
-12\end{array}$ & $\begin{array}{l}4.5 \\
4.8 \\
5.0 \\
5.5 \\
6.0 \\
5.8 \\
5.3 \\
6.0 \\
7.4 \\
7.4 \\
6.4\end{array}$ & $\begin{array}{r}110 \\
107 \\
106 \\
101 \\
101 \\
106 \\
102 \\
105 \\
98 \\
95 \\
92\end{array}$ & $\begin{array}{l}\prime \prime \\
\prime \prime \\
\prime \prime \\
\prime \prime \\
\prime \prime \\
\prime \prime \\
\prime \prime \\
\prime \prime \\
\prime \prime \\
\prime \prime \\
\prime \prime\end{array}$ & 11 & $\begin{array}{l}109 \\
110 \\
111 \\
112 \\
113 \\
114 \\
115 \\
116 \\
117 \\
118 \\
119\end{array}$ & $\begin{array}{l}0.57 \\
0.51 \\
0.58 \\
0.50 \\
0.47 \\
0.49 \\
0.49 \\
0.36 \\
0.32 \\
0.30 \\
0.22\end{array}$ & $\begin{array}{l}33 \\
38 \\
30 \\
31 \\
41 \\
40 \\
42 \\
27 \\
37 \\
47 \\
34\end{array}$ & $\begin{array}{l}6.3 \\
6.0 \\
6.0 \\
6.3 \\
5.3 \\
4.5 \\
4.0 \\
4.5 \\
4.5 \\
4.5 \\
4.5\end{array}$ & $\begin{array}{l}81 \\
83 \\
88 \\
89 \\
88 \\
87 \\
85 \\
85 \\
74 \\
78 \\
84\end{array}$ & $\begin{array}{l}\text { 開 } \\
\prime \prime \\
\prime \prime \\
\prime \prime \\
\prime \prime \\
\prime \prime \\
\prime \prime \\
\text { 閉 } \\
\prime \prime \\
\prime \prime \\
\prime \prime\end{array}$ \\
\hline
\end{tabular}




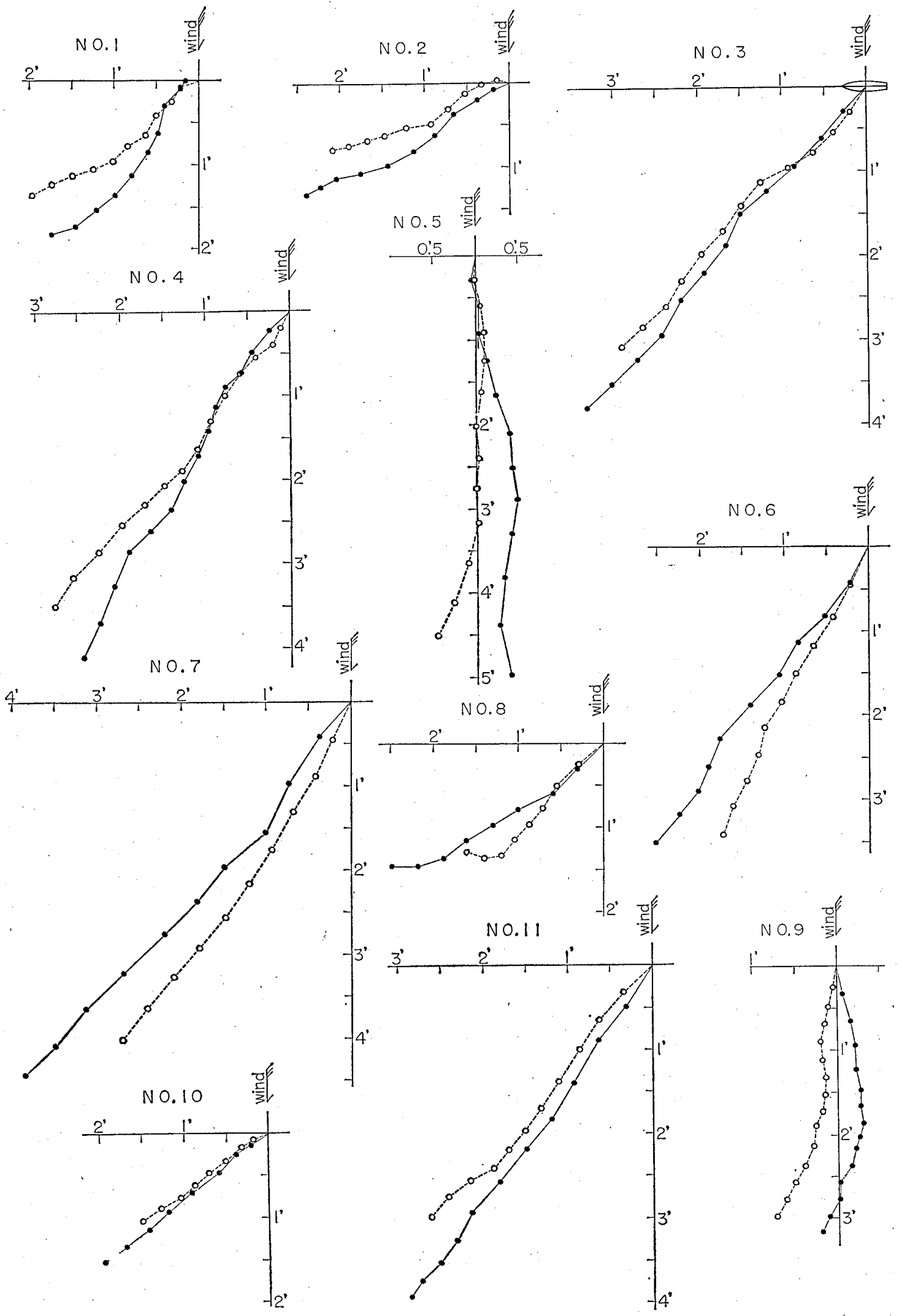

図 2 漂流および漂流推定図

ㅇ, 実線…漂流位置, 方向

○，点線……推定位置, 方向 
連および実用化重視の立場において無視することにした。

\section{3. 漂 流 実 験}

昭和 43 年 6 月 4 日より 9 日まで，15日より20日までの二航海は千島列島南方海域において，ま た 7 月 2 日より 12 日までオホーツク海で，同船について次の要領で漂流実験を行なつた。

\section{1 漂流船位の測定}

長さ約 $3 \mathrm{n} . \mathrm{m}$. ., 深さ約 $7 \mathrm{~m}$ の流網にとりつけた corner reflector を観測の原点とし，観測者は これの方位・距離を 30 分ごとに Radar により測定し，基点に対する現在位置を求めた。かくす れば各30分間に㧍ける風圧による漂流状況は容易に求められるが，漂流量，漂流方向 $(\beta)$ およ び推定に必要な風速，船首方向 $(\alpha)$ を掲記したのが表 1 である。

\section{2 漂流船位の推定}

course recorder に記録されだ船首方位の平均值と平均風向の差角および平均風速により前記 推定式に基づいて30分ごとの位置を計算し推定船位とした。

\section{3 結}

\section{果}

各日に抒ける30分ごとの漂流位置扝よび推定位置を画いたのが図2である。

総括的にみて各日に扔ける両者の漂流開始地点と終了地点を結ぶ方向 (Co. m. g.), 距離 (Dist. m. g.) の違いはそれぞれ $10^{\circ} ， 1$ n. m. 程度に収まつている。

\section{4. 推定船位の精度}

測定位置に対する推定位置のず れを表示する方法としては，直交 座標に招ける縦，横軸の長さ，あ るいは極座標における極角，動径 をもつてするのが普通であるが， この点については前項より判断す ることにして, 本項では漁具監視 上最も直接的な表示法すなわち原 点 (漁具) に対する方向のずれと 漂流位置，推定位置間の長さをも ってし（それぞれを方向誤差，距 離誤差と呼称）検討することにす

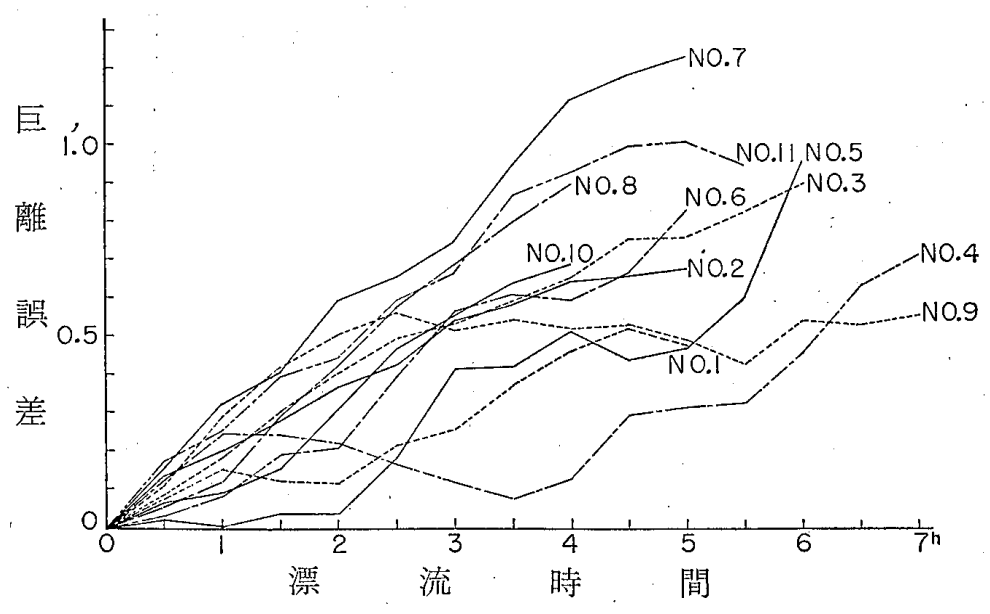

図 3 漂流位置, 推定位置間の距離と漂流時間の関係

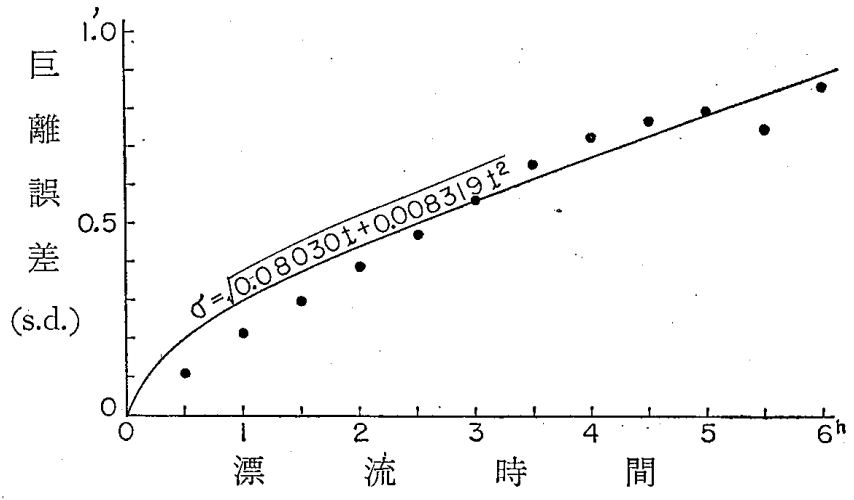

図 4 䟚離誤产と漂流時間の関倸

\section{1 距 離 誤 差}

漂流位置と推定位置の間の長さを各観測 日ごとに漂流時間との関係において示した のが図 3 である。それらの長さは漂流方 向, 距離の推定䛊差の現わ机具合によつて きまるので，一般則的な関係は見出だし難 いが，各時閒ごとの標準偏差を求めてみる と図 4 に見るごとく, 距離誤差と漂流時間 との間には, 


$$
\begin{aligned}
\sigma^{(\prime)} & =\sqrt{0.08030 t+0.008319 t^{2}} \\
& \fallingdotseq 0.09 \sqrt{10 t+t^{2}}
\end{aligned}
$$

( $t$ 単位：時）

なる関係汃兒られる。

操業漁船に扔いて漁具を投じて より揚げるまでの最長漂流時間は 一概にいえないが，8時間と多て も推定位置は 漈流位置と s.d. で ln.m. 程度のずれを示すに過ぎな i。

\section{2 方向 䛊 差}

漂流方向を図1のごとく測り， 推定方向一漂流方向を各観測日ご とに漂流時間との関連で示したの が図 5 であつて，2，3時間経つと相当安 定してくる。漂流初期に㧍いてばらつきが 大きいのは，わずかの推定誤差も角度に敏 感に響くといら当然の現象を示しているに 過ぎない。

また各時間ごとの標隻偏至を plotして みると図6のごとくで，時間の経過につれ て方向誤差が避減していくのは，偶然誤差 の平均化による精度の向上と見られるが， 聥減率は方向請差の他に距離詰差が入つて いるので簡単ではないが，図6より単純に $a t^{n}$ を想定して各係数を求めてみると $13{ }^{\circ} 28 t^{-0.32} \fallingdotseq 13^{\circ} / \sqrt[3]{t}$ が導かれ， $t$ を 8 時間とすれば方向 㟪差注 s.d. で約 $7^{\circ}$ である。

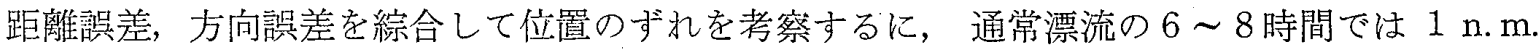
程度，方向のずれは $7^{\circ}$ 程度であり，逆に極く短時間内では方向の推定精度は悪いが位置そのも ののずれは数百米以内であるので，漁具監視上の支障はない。

また表 1 の資料全部について連続漂流したものと仮定してみると，漂流時閒 59.5 時間につい て, 漂流距離 $=41 .{ }^{\prime} 0$, 漂流与向 $=34 .{ }^{\circ} 6$ に対し推定漂流距離 $=35 .{ }^{\prime} 3$ ，推定方向 $=35 .{ }^{\circ} 8$, 漂流位置 と推定位置の間の長さは 5.'7である。ここに漂流量を各観測時における船の状態，海象状態に適 合するごとく補正すれば，推定位置の精度は向上する筈であるが，漂流位置の推定は監視上補助 的，予備的な性格をもつものであることより；簢便であることに重点を拉き修正の煩を避けた。

\section{5. 結言}

漁具監視の立場から要求される推定船位の精度は，海象，気象，時刻，装備によつて異なるの で画一的にはきめられない汸，漂流終了地点より帰投行動に移る際針路を決定できる条件を備え ていることがまず必要である。次に目漂に接近し視認距離に入れ垱然目標の発見に注力する が，ての時機执よび見張りの重点方向を予知しらることも大切である。 
筆者らの用いた方法によれば，通常の漂流時間に対し，漂流方向のばらつきは標準偏差で $7^{\circ}$ 程度であるので視認距離に達した時点に晾いて目標を発見することは難かしくない。（もちろん 見張りの重点範囲酒流終了地点より見張りの開始地点までの距離によつて異なる。）をた漂流 位置と推定位置の間の距離は $1 \mathrm{n} . \mathrm{m}$. (s.d.) 程度であるので帰投時間についての情報を得ること も難かしくない。

このように直接的に漁具の監視に有効であり，また従来どおりの監視法をとる場合でも補助的 に，あるい機器の故障に対する予備的な効果も踊えている。総括的にいえば監視に対する労力 の軽減，直接，間接監視が可能であることに対する安心感は実用上有効であると思考する。この ような観点より各船それぞれ自船の漂流特性定研究して，漁具監視に適用されんことを期街する ものである。

参 考 文 献

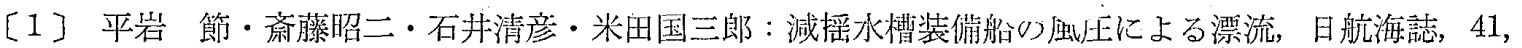
(1969) pp. 141

\section{[澌疑応答〕}

漂流船位の詥差を推定するに当つて，風速の大小による影響の相違について考慮されているの でしょうか。風速が大となり篎天となればなるほど船位の推定誤差は大きくなりますが，その影 響度を判定するのは，極めてむつかしい事と存じますが。

(長谷川健二)

\section{[解答]}

漂流船位推定の方法は前報（会誌41号）の実験結果に基づいて行なつたものです。漂流量のば らつきは風速の関数ではないのかとの御翼問ですが，同誌図 2 に見るごとく操業可能範国では洘 慮の必要を認めませんでした。つぎに漂流方向と風速との関係について注，同誌図 5 より漂流方 向漂流姿態（船首方向）に関連するが，船首方向と風速海無相関であることより（図 3)，風 速の大小によつて漂流方向が一義的にきまると㛈えられません。したがつて，方向，距離の推 定誤差は風速を parameter とする必要がないと考えています。 